\title{
Efficacy of sulfadoxine-pyrimethamine in Tanzania after two years as first-line drug for uncomplicated malaria: assessment protocol and implication for treatment policy strategies
}

\author{
Kefas Mugittu1,2, Salim Abdulla ${ }^{1}$, Nicole Falk², Honorati Masanja ${ }^{1,2}$, \\ Ingrid Felger ${ }^{2}$, Hassan Mshinda1, Hans-Peter Beck ${ }^{2}$ and Blaise Genton*2
}

\author{
Address: ${ }^{1}$ Ifakara Health Research and Development Centre (IHRDC), P. O. Box 53, Ifakara, Tanzania and ${ }^{2}$ Swiss Tropical Institute, Socinstrasse \\ 57, 4002 Basel, Switzerland \\ Email: Kefas Mugittu - kefas.mugittu@unibas.ch; Salim Abdulla - salim.abdulla@gmail.com; Nicole Falk - nicole.falk@stud.unibas.ch; \\ Honorati Masanja - honorati.masanja@unibas.ch; Ingrid Felger - ingrid.felger@unibas.ch; Hassan Mshinda - hmshinda@ifakara.mimcom.net; \\ Hans-Peter Beck - hans-peter.beck@unibas.ch; Blaise Genton* - blaise.centon@hospvd.ch \\ * Corresponding author
}

Published: 18 November 2005

Malaria Journal 2005, 4:55 doi:10.1/86/1475-2875-4-55

This article is available from: http://www.malariajournal.com/content/4/I/55

(C) 2005 Mugittu et al; licensee BioMed Central Ltd.

This is an Open Access article distributed under the terms of the Creative Commons Attribution License (http://creativecommons.org/licenses/by/2.0), which permits unrestricted use, distribution, and reproduction in any medium, provided the original work is properly cited.
Received: 23 August 2005

Accepted: 18 November 2005

\begin{abstract}
Background: Systematic surveillance for resistant malaria shows high level of resistance of Plasmodium falciparum to sulfadoxine-pyrimethamine (SP) across eastern and southern parts of Africa. This study assessed in vivo SP efficacy after two years of use as an interim first-line drug in Tanzania, and determined the rates of treatment failures obtained after 14 and 28 days of follow-up.

Methods: The study was conducted in the Ipinda, Mlimba and Mkuranga health facilities in Tanzania. Children aged 6-59 months presenting with raised temperature associated exclusively with P. falciparum (I,000-100,000 parasites per $\mu \mathrm{l})$ were treated with standard dose of SP. Treatment responses were classified according to the World Health Organization (WHO) definition as Adequate Clinical and Parasitological Response (ACPR), Early Treatment Failure (ETF), Late Clinical Failure (LCF) and Late Parasitological Failure (LPF) on day I4 and day 28.
\end{abstract}

Results: Overall $196(85.2 \%)$ of 230 patients had ACPR on day I 4 but only II $6(50.9 \%)$ on day 28 (57.7\% after excluding new infections by parasite genotyping). Altogether 21 (9.1\%) and I3 (5.7\%) of the 230 patients assessed up to day 14 and 39 (17.1\%) and $55(24.1 \%)$ of the 228 followed up to day 28 had clinical and parasitological failure, respectively.

Conclusion: These findings indicate that SP has low therapeutic value in Tanzania. The recommendation of changing first line treatment to artemether + lumefantrine combination therapy from early next year is, therefore, highly justified. These findings further stress that, for long half-life drugs such as SP, establishment of cut-off points for policy change in high transmission areas should consider both clinical and parasitological responses beyond day I4.

\section{Background}

There is controversy over the therapeutic life of sulfadoxine-pyrimethamine (SP) when used alone for the treat- ment of uncomplicated malaria in Africa. Experts do not all agree on which drug efficacy measurements more accurately predict usefulness of a drug in a community. Some 
Table I: Mean age, temperature, haemoglobin and parasite density on admission day

\begin{tabular}{|c|c|c|c|c|c|}
\hline \multirow[t]{2}{*}{ Site } & \multicolumn{5}{|c|}{ Means } \\
\hline & Weight in $\mathbf{k g ( S D )})^{\prime}$ & Age in years (SD)' & Temperature in ${ }^{\circ} \mathrm{C}$ (SD) ${ }^{\prime}$ & $H b^{\prime}$ in $g / d l(S D)^{\prime}$ & parasites/ $\mu \mathrm{l}$ (SD) \\
\hline Ipinda $(n=73)$ & $10.7(2.9)$ & I.7(I.3) & $38.4(1.0)$ & $9.4(1.6)$ & 3 I'499 $(30,260)$ \\
\hline Mlimba $(n=75)$ & II.0(2.9) & I.7(1.4) & $38.3(0.9)$ & $9.0(1.6)$ & $53,206(30,782)$ \\
\hline Mkuranga $(n=93)$ & $10.9(3.7)$ & $1.3(1.0)$ & $38.7(0.8)$ & $8.6(1.9)$ & $44,877(38,572)$ \\
\hline
\end{tabular}

$\mathrm{Hb}=$ haemoglobin; $\mathrm{SD}=$ standard deviation

consider clearance of symptoms alone [1] or plus parasites by day 14, as advised by the World Health Organization [Regional Office for Africa (WHO/AFRO) Consultative Meeting on Antimalarial Policy in the Africa Region, $14^{\text {th }}-15^{\text {th }}$ August 2003, Harare, Zimbabwe]. Others regard clearance of both symptoms and parasites over a much longer period as the most accurate measure of drug effectiveness [2-4].

The assessment methodology has profound implications in terms of treatment policy strategies. Attempts have been made to define the cut-off points for changing firstline malaria treatment. Using the old treatment response classification criteria, the action period was due when a combined Early Treatment Failure (ETF) and Late Treatment Failure (LTF) were between $16-24 \%[4,5]$. A couple of years ago, WHO/AFRO recommended $15 \%$ clinical and $25 \%$ parasitological treatment failure rates at day 14 as cut-off points for implementation of policy change in intense transmission areas (WHO/AFRO consultative meeting on antimalarial policy in the Africa region, $14^{\text {th }}$ $15^{\text {th }}$ August 2003, Harare, Zimbabwe).

Systematic surveillance for efficacy of antimalarial drugs shows increasing levels of Plasmodium falciparum resistance to SP across eastern and southern parts of Africa $[6,7]$. In 2001, Tanzania adopted SP as interim first-line treatment for uncomplicated malaria while awaiting for the results of different combination therapies trials. As part of the National Malaria Control Programme (NMCP), this study assessed in vivo SP efficacy after two years of widespread use in Tanzania.

\section{Methodology}

The study was conducted from July to November 2003 in the Ipinda (south-west), Mlimba (south-east) and Mkuranga (east) health facilities in Tanzania. Malaria transmission in these areas is perennial with peaks between May and July. A slightly modified WHO antimalarial drug efficacy testing protocol [8] was used, so as to conform with another study that was being conducted at the same time under the same project framework in Papua New Guinea, in areas with lower levels of endemicity.
Children aged 6-59 months presenting with raised temperature $\left(37.5^{\circ} \mathrm{C}-39.5^{\circ} \mathrm{C}\right)$ associated with $P$. falciparum parasitaemia between 1,000-100,000 parasites per $\mu \mathrm{l}$ were recruited. Exclusion criteria and other procedures were as detailed in the protocol [8]. Patients were treated (under observation) with a standard dose of SP (Fansidar ${ }^{\circledast}$ Roche), i.e $1.25 \mathrm{mg} / \mathrm{kg}$ of pyrimethamine and $25 \mathrm{mg} / \mathrm{kg}$ of sulfadoxine. The responses were classified according to the new WHO definition as ACPR, ETF, LCF and LPF at day 14 and day 28 [8].

Treatment failures rates were corrected after genotyping the $m s p 2$ locus to detect new infections. Extensive diversity in this locus has been observed with over 84 allelic variants in south-eastern Tanzania $[9,10]$ and other investigators observed high genotype complexity with an average of 4.9 genotypes per asymptomatic individual in eastern Tanzania [11]. These observations are suggestive that $m s p 2$ alone may sufficiently discriminate recrudescence from reinfection in Tanzania. It has previously been shown that analysis of $m s p 2$ locus alone can effectively distinguish recrudescence from reinfection in Uganda [12]. The clinical and molecular data were combined and analysed using Stata version 8.0 (Stata Corporation Inc, Texas, USA).

\section{Results}

A total of 241 patients were recruited, of which 13 were lost to follow-up. Table 1 summarizes patient age and clinical parameters recorded on admission day by site. Table 2 provides details of treatment outcome by site. On day 28, only 116 (50.9\%) of the 228 patients showed ACPR. Molecular genotyping showed that 27/112 $(24.5 \%)$ recurrent infections were due to re-infections, therefore were excluded from the analysis and recorded as withdrawn. Hence, PCR-corrected ACPR was 116/201 (57.7\%). 196 (85.2\%) of the 230 patients had ACPR by day 14 .

The total clinical failure by day 14 and 28 was observed in $21(9.1 \%)$ out of 230 and $39(17.1 \%)$ out of 228 patients, respectively. $13(5.7 \%)$ and $55(24.1 \%)$ of the patients had LPF by day 14 and 28, respectively. Thus 34 (14.9\%) 
Table 2: Sulfadoxine-pyrimethamine treatment outcomes

\begin{tabular}{|c|c|c|c|c|c|c|c|c|c|}
\hline Results & $\begin{array}{l}\text { no. of included } \\
\text { patients }\end{array}$ & $\begin{array}{l}\text { LF and } \\
\text { corr. }\end{array}$ & $\begin{array}{l}\text { Evaluable } \\
\text { patients }\end{array}$ & $\begin{array}{l}\text { ACPR } \\
\text { n (\%) }\end{array}$ & $\begin{array}{l}\text { ETF } \\
\text { n (\%) }\end{array}$ & $\begin{array}{l}\text { LCF } \\
\text { n (\%) }\end{array}$ & $\begin{array}{l}\text { Total CF } \\
\text { n (\%) }\end{array}$ & $\begin{array}{l}\text { LPF } \\
\text { n (\%) }\end{array}$ & $\begin{array}{l}\text { Overall TF } \\
\text { n (\%) }\end{array}$ \\
\hline \multicolumn{10}{|l|}{ At D I4 } \\
\hline Ipinda & 73 & 1 & 72 & $62(86.1)$ & $7(9.7)$ & $2(2.8)$ & $9(12.5)$ & $\mathrm{I}(\mathrm{I} .4)$ & $10(13.9)$ \\
\hline Mlimba & 75 & 3 & 72 & $63(87.5)$ & $3(4.3)$ & $4(5.7)$ & $7(9.1)^{\prime}$ & $2(2.9)$ & $9(12.9)$ \\
\hline Mkuranga & 93 & 7 & 86 & $71(82.6)$ & $3(3.5)$ & $2(2.3)$ & $5(6.9)$ & $10(11.6)$ & $15(17.4)$ \\
\hline Total & 241 & 11 & 230 & $196(85.2)$ & $13(5.7)$ & $8(3.5)$ & $21(9.1)$ & $13(5.7)$ & $34(14.9)$ \\
\hline \multicolumn{10}{|l|}{ At D28 } \\
\hline Ipinda & 72 & 0 & 72 & $44(61.1)$ & $7(9.7)$ & $5(6.9)$ & $12(16.7)$ & $16(22.2)$ & $28(38.9)$ \\
\hline Mlimba & 72 & 2 & 70 & $34(48.6)$ & $3(4.3)$ & $9(12.9)$ & $12(17.1)$ & $24(34.3)$ & $36(51.4)$ \\
\hline Mkuranga & 86 & 0 & 86 & $38(44.2)$ & $3(3.5)$ & $12(13.9)$ & $15(17.4)$ & $33(38.4)$ & $48(55.8)$ \\
\hline Total & 230 & 2 & 228 & $116(50.9)$ & $13(5.7)$ & $26(I I .4)$ & $39(17.1)$ & $55(24.1)$ & $112(49.1)$ \\
\hline \multicolumn{10}{|c|}{ At D28 PCR-corrected } \\
\hline Ipinda & 72 & 6 & 66 & $44(66.7)$ & $7(9.7)$ & $5(6.9)$ & $12(16.7)$ & $10(13.9)$ & $22(33.3)$ \\
\hline Mlimba & 70 & 10 & 60 & $34(56.7)$ & $3(4.3)$ & $5(7.1)$ & $8(11.4)$ & $18(25.7)$ & $26(43.3)$ \\
\hline Mkuranga & 86 & 11 & 75 & $38(50.7)$ & $3(3.5)$ & $8(9.3)$ & $\mathrm{II}(12.8)$ & $26(30.2)$ & $37(49.3)$ \\
\hline Total & 228 & 27 & 201 & $116(57.7)$ & $13(5.7)$ & $18(7.9)$ & $31(13.6)$ & $54(23.7)$ & $85(42.3)$ \\
\hline
\end{tabular}

ACPR = Adequate Clinical and Parasitological Response; TF = Treatment failure, ETF = Early Treatment Failure, LCF = Late Clinical Failure; LPF = Late Parasitological Failure; CF = Clinical failure, $n=$ Sample Size; TF = Treatment failure, FP = Lost to Follow-up, corr. $=$ corrected

out of 230 and $112(49.1 \%)$ out of 228 patients had overall treatment failure by day 14 and 28, respectively. After genotyping recurrent infections day-28 treatment failures decreased to 85 (42.3\%). In this study Mkuranga recorded the highest rates of both PCR-adjusted and unadjusted treatment failures followed by Mlimba and Ipinda.

\section{Discussion}

In 2001 Tanzania replaced chloroquine with SP as interim first-line antimalarial drug. Prior to this change, baseline clinical trials with SP had been conducted throughout the country using the 14 day follow-up protocol, and indicated an average efficacy of $86 \%$ on day 14 . These findings paved the way for the malaria treatment policy change [13] and SP is still used as first line antimalarial drug in Tanzania. The present study assessed SP efficacy (using a 28 day follow-up) in three sites in Tanzania after two years of use as first-line antimalarial drug. With this extended period of follow-up, half of the patients (49.1\%) failed treatment. Even when new infections were taken into account by genotyping, the overall treatment failure rate $(42.3 \%)$ was still high. This level of resistance is close to that observed in Muheza (45\%), an area of high SP resistance in Tanzania [14].

Restricting our analysis to outcomes at day 14 would have led to misleadingly low clinical (9.1\%) and parasitological $(5.7 \%)$ treatment failure rates with the overall treatment failure (14.9\%) being equal to that recorded at baseline prior to policy change. Using a shorter follow-up period, another study in parts of Tanzania also recorded an overall SP treatment failure of only 9.2\% [15]. According to WHO/AFRO proposed thresholds for policy change (i.e $15 \%$ and $25 \%$, respectively), these failure levels would still be considered acceptable. Retention of SP clinical efficacy at day 14 after 10 years of its use as first-line drug has been demonstrated in Malawi [1]. However, extending the follow-up to day 28 the total failure was as high as $66 \%$. Even at day 14 the clinical and total failure rates were far above $15 \%$ and 25\%, respectively. As in Malawi, the majority of the recurrent infections in our study were LPFs observed between day 14 and 28. The new WHO efficacy testing protocol [8] recommends follow up for 28 days for drug with long half-life such as SP, if genotyping can be done to distinguish recrudescence from re-infections. When efficacy assessment is based only on clearance of symptoms in the first 14 days, the level of parasite resistance can be grossly underestimated. It is widely accepted that clearance of both parasitaemia and symptoms is the most accurate measure of the intrinsic resistance of the parasite to a drug [2-4]. The resistant parasite that is apparently causing asymptomatic infection in LPF is likely to lead in the short-term to a new clinical episode [14] and/or to anaemia, depending on the immunity of the subject.

Our observations show that SP efficacy in Tanzania is compromised and fully justify the recent decision to review the current malaria treatment policy from early next year in favour of artemether + lumefantrine combination therapy. This recommendation should be implemented at a large scale as soon as possible. Such a change would be welcome to protect the use of SP in its indication for the intermittent preventive treatment of pregnant women (IPTp). Indeed, it is at present the only drug that can be used for IPTp purpose because of its good safety profile. As far as methodology is concerned, the findings stress that cut-off points for malaria treatment policy 
change in high transmission areas should consider both clinical and parasitological responses beyond day 14 , coupled with distinction of recrudescence from re-infection using molecular genotyping.

\section{Authors' contributions}

B. Genton, H-P. Beck and K. Mugittu designed the study. S. Abdulla and K. Mugittu organised the clinical work. H. Mshinda was the supervisor in Tanzania. N. Falk, I. Felger, H-P. Beck performed molecular genotyping. H. Masanja carried out the statistical analysis. K. Mugittu and B. Genton wrote the article and all others contributed to it.

\section{Ethical approval}

The study was approved by the Tanzanian national and institutional ethics bodies

\section{Acknowledgements}

We are grateful to the Tanzania Ministry of Health $(\mathrm{MoH})$, National Malaria Control Program (NMCP). We are thankful to the on-site clinical and field officers, nurses and parents/guardians who consented to participate and to Prof. M. Tanner for his critical comments on the manuscript. This study was funded jointly by the European Union (Grant no. QLK2-CT-2002-01503, BBW 03.000I) and the Swiss National Foundation for Science (Grant no. 3100-067260). IHRDC receives core financial support from Swiss Agency for Development and Co-operation. Kefas Mugittu's PhD training programme is supported by Research Training Grants from the UNICEF/ UNDP/World Bank/WHO Special Programme for Research and Training in Tropical Diseases (TDR).

\section{References}

I. Plowe CV, Kublin JG, Dzinjalamala FK, Kamwendo DS, Mukadam RA, Chimpeni P, Molyneux ME, Taylor TE: Sustained clinical efficacy of sulfadoxine-pyrimethamine for uncomplicated malaria in Malawi after 10 years as first-line treatment: five year prospective studies. Brit Med I 2004, 328:545-548. Responses from White N, Ringwald P and authors' reply. Sulfadoxine-pyrimethamine for uncomplicated falciparum malaria. BM] 328: I259-1260.

2. Sibley $\mathrm{CH}$, Hunt SY: Drug resistance in parasites: can we stay ahead of the evolutionary curve? Trends Parasitol 2003, 19:532-537.

3. Stepniewska K, Taylor WR, Mayxay M, Price R, Smithuis F, Guthmann JP, Barnes K, Myint HY, Adjuik M, Olliaro P, Pukrittayakamee S, Looareesuwan S, Hien TT, Farrar J, Nosten F, Day NP, White NJ: In vivo assessment of drug efficacy against Plasmodium falciparum malaria: duration of follow-up. Antimicrob Agents Chemother 2004, 48:427I-4280.

4. World Health Organization: The use of antimalarial drugs. Report of a WHO informal Consultation, 13-17 November 2000. WHO/ CDS/RBM/200I.33 [http://rbm.who.int/cmc upload/0/000/014/923/ am toc.htm]. WHO Geneva

5. World Health Organization: Antimalarial drug combination therapy: Report of a WHO informal Consultation, 4-5 April 200I. WHO/CDS/RBM/200I.35 200I [http://www.paho.org/Eng lish?AD/DPC/CD?mal-adot.htm]. WHO Geneva

6. East Africa Network for Monitoring Antimalarial Treatment: Monitoring antimalarial drug resistance within national malaria control programmes: the EANMAT experience. Trop Med Int Health 2001, 6:891-898.

7. Wongsrichanalai C, Pickard AL, Wernsdorfer WH, Meshnick SR: Epidemiology of drug-resistant malaria. Lancet Infect Dis 2002, 2:209-218.

8. World Health Organization (WHO): Monitoring antimalarial drug resistance. In report of a WHO informal consultation, 3-5 December 2001: WHO/CDS/RBM/2002.39. Geneva [http://www.who.int/ malaria/cmc upload/0/000/015/800/200239.pdf].
9. Felger I, Smith T, Edoh D, Kitua A, Alonso P, Tanner M, Beck HP: Multiple Plasmodium falciparum infections in Tanzanian infants. Trans R Soc Trop Med Hyg 1999, 93(Suppl I):29-34.

10. Felger I, Irion A, Steiger S, Beck HP: Genotypes of merozoite surface protein 2 of Plasmodium falciparum in Tanzania. Trans $R$ Soc Trop Med Hyg 1999, 93(Suppl I):3-9.

II. Magesa SM, Mdira KY, Babiker HA, Alifrangis M, Farnert A, Simonsen PE, Bygbjerg IC, Walliker D, Jakobsen PH: Diversity of Plasmodium falciparum clones infecting children in a holoendemic area in north-eastern Tanzania. Acta Trop 2002, 84:83-92.

12. Cattamanchi A, Kyabayinze D, Hubbard A, Rosenthal PJ, Dorsey G: Distinguishing recrudescence from re-infection in a longitudinal antimalarial drug efficacy study: comparison of results based on genotyping of MSP-I, MSP-2, and GLURP. Am J Trop Med Hyg 2003, 68:133-139.

13. Mugittu K, Ndejembi M, Malisa A, Lemnge M, Premji Z, Mwita A, Nkya W, Kataraihya J, Abdulla S, Beck HP, Mshinda H: Therapeutic efficacy of sulfadoxine-pyrimethamine and prevalence of resistance markers in Tanzania prior to revision of malaria treatment policy: Plasmodium falciparum dihydrofolate reductase and dihydropteroate synthase mutations in monitoring in vivo resistance. Am J Trop Med Hyg 2004, 71:696-702.

14. Mutabingwa T, Nzila A, Mberu E, Nduati E, Winstanley P, Hills E, Watkins W: Chlorproguanil-dapsone for the treatment of drug resistant falciparum malaria. Lancet 200I, 358:1218-I 223.

15. Lemnge MM, Ali AS, Malecela EK, Sambu E, Abdulla R, Juma MS, Fakih $\mathrm{K}$, Abdulla $\mathrm{KH}$, Njau RJ: Therapeutic efficacy of sulfadoxinepyrimethamine and amodiaquine among children with uncomplicated Plasmodium falciparum malaria in Zanzibar, Tanzania. Am J Trop Med Hyg 2005, 73:68I-685.
Publish with BioMed Central and every scientist can read your work free of charge

"BioMed Central will be the most significant development for disseminating the results of biomedical research in our lifetime. "

Sir Paul Nurse, Cancer Research UK

Your research papers will be:

- available free of charge to the entire biomedical community

- peer reviewed and published immediately upon acceptance

- cited in PubMed and archived on PubMed Central

- yours - you keep the copyright

Submit your manuscript here:

http://www.biomedcentral.com/info/publishing_adv.asp
BioMedcentral 